\title{
HISTOPATHOLOGICAL EVALUATION OF GASTRO PROTECTIVE EFFECT OF TRIGONELLA FOENUM GRAECUM SEED (METHI) AND OMEPRAZOLE IN EXPERIMENTALLY INDUCED GASTRIC ULCER IN RATS
}

\author{
AFROZ R ${ }^{1}$, KHAN I ${ }^{2}$, RAHMAN KA ${ }^{3}$, LOTUS MJ ${ }^{4}$, SHAHABUDDIN MMS ${ }^{5}$, YEASMIN N ${ }^{6}$, AFRIN T ${ }^{7}$, \\ MOON KJ ${ }^{8}$
}

\begin{abstract}
Context: Peptic ulcer is a common disorder of the stomach and duodenum. Bangladesh is a developing country with a very high point prevalence of duodenal ulcer disease (11.9\%) and a $H$. pylori prevalence of more than $90 \%$ in asymptomatic adults and $80 \%$ in children at the age of 5 years. The multifactorial pathogenesis of peptic ulcers is secretion of gastric acid. The main therapeutic target is the control of this secretion using antacids, $\mathrm{H} 2$ receptor blockers (ranitidine, famotidine) or proton pump blockers (omeprazole and lansoprazole). However, nowadays, gastric ulcer therapy faces a major drawback because most of the drugs currently available in the market show limited efficacy against gastric diseases and are often associated with severe side effects. Thus, there is an urgent need to identify more effective and safe antiulcer agents. In this context, the use of medicinal plants for the prevention and treatment of different pathologies is in continuous expansion worldwide. From the ancient time, various plants were used in traditional medicine with reputation as efficacious remedies. The list of plant derived modern medicine is very long now. About 33\% of the drugs produced in the developed countries are derived from plants. Trigonella foenum-graecum (Fenugreek, Methi) is one of them used in many parts of world. Preliminary study on animal showed that Trigonella foenum-graecum seed has significant gastro-protective effect. A study was carried out to demonstrate the gastro-protective effect of aqueous extract and ethanolic extract of Trigonella foenum-graecum seed (Fenugreek, Methi) and omeprazole on ethanol induced gastric ulcer in experimental rats.
\end{abstract}

Material and Methods: The present study was performed on 24 (twenty four) rats which were divided randomly into 4 groups each having 6 rats in the Pharmacology Department of Dhaka Medical college, Dhaka. $1 \mathrm{ml}$ of absolute ethanol ( $5 \mathrm{ml} / \mathrm{kg}$ body wt.) was orally administered to all groups by gastric intubations to induce gastric ulcer in all groups except normal control. Omeprazole suspension $(20 \mathrm{mg} / \mathrm{kg}$ body wt) was used as synthetic anti ulcer drug in study. Aqueous and ethanolic extract of Trigonella foenum-graecum seed(500 $\mathrm{mg} / \mathrm{kg}$ body wt) were used respectively orally. Histopathological analysis was carried out to evaluate the gastroprotective activity of aqueous and ethanolic extract of Trigonella foenum-graecum seed and omeprazole on ethanol induced gastric ulcer in experimental rats.

Result: Pretreatment with aqueous and ethanolic extract of Trigonella foenum-graecum seed $(500 \mathrm{mg} / \mathrm{kg} /$ body wt) showed very significant prevention in ethanol induced gastric ulcer. Results of the study showed that in case of ethanol treated rats gross examination showed a large amount of haemorrhagic lesions confined mostly in the gastric corpus. Histologically lesion involved about two-third of the mucosa layer and exfoliation of the mucosal cells was detected. Meanwhile, red blood cells were present in the gastric mucosa and edematous submucosa was discovered. However aqueous and ethanolic extract of Trigonella foenum-graecum seed significantly reduced the haemorrhagic lesions, tissue proliferation, infiltration of cells and sloughing induced by ethanol. This prevention was statistically very significant $(P<0.001)$.

Conclusion: The aqueous and ethanol extracts of Trigonella foenum-graecum seed and omeprazole possess gastro protective properties.

Key words : Gastro-protective, histopathology, Trigonella foenum graecum seed (Methi) extract, omeprazole, gastric ulcer.

J Dhaka Med Coll. 2019; 28(1) : 67-75

1. Dr. Rumana Afroz, Assistant Professor, Department of Pharmacology. Dhaka Medical College, Dhaka.

2. Prof. Dr. Md. Ismail khan, VC, Chittagong Medical University.

3. Dr. Kazi Afzalur Rahman, Associate Professor, Department of Pharmacology, Dhaka Medical College, Dhaka.

4. Dr. Mahbuba Jahan Lotus, Assistant Professor, Department of Pharmacology. Dhaka Medical College, Dhaka.

5. Dr. Mir muhammad Shoyeb Shahabuddin, Assistant Professor, Department of Pharmacology, Sheikh Hasina Medical College, Jamalpur.

6. Dr. Tasnin Afrin, Assistant Professor, Department of Pharmacology. Dhaka Community Medical College, Dhaka.

7. Dr. Nahid Yeasmin, Assistant Professor, Department of Physiology, Dhaka Medical College, Dhaka.

8. Dr. Kawsar Jahan Moon, Assistant Professor, Department of Pharmacology, Chittagong Medical College, Dhaka. Correspondence : Dr. Rumana Afroz, Assistant Professor, Department of Pharmacology, Dhaka Medical College, Dhaka, Cell Phone: +8801712027705, E-mail: rumana.k54@gmail.com

Received: 10 February 2019

Revision: 02 March 2019

Accepted: 30 Mach 2019

DOI: https://doi.org/10.3329/jdmc.v28i1.45759 


\section{Introduction:}

For more than a century peptic ulcer disease has been a major cause of morbidity and mortality. Duodenal ulcer is common in Bangladesh. In Bangladesh, the prevalence of duodenal ulcer and gastric ulcer was estimated to be $11.98 \%$ and $3.58 \%$ respectively ${ }^{1}$. The term peptic ulcer disease is used broadly to include ulcerations and erosions in the stomach and duodenum from a number of causes ${ }^{2}$. Peptic ulcer is a break in the gastric or duodenal mucosa that arises when the normal mucosal defensive factors are impaired or are overwhelmed by aggressive luminal factors such as acid and pepsin. The ulcers extend through the muscularis mucosae and are usually over $5 \mathrm{~mm}$ in diameter ${ }^{3}$. The gastrointestinal defense mechanisms include gastric mucosal integrity, mucus secretion, bicarbonate production, nitric oxide (NO), gastroprotective prostaglandin synthesis, normal gastric motility, and adequate tissue microcirculation, while the noxious factors comprise, among others, gastric acid and pepsin secretion, bile salts, reactive oxygen species (ROS), Helicobacter pylori infection, alcohol consumption, and prolonged ingestion of nonsteroidal anti-inflammatory (NSAIDs) drugs $^{4-6}$.

Gastric ulcer can be prevented by reducing the gastric acid production and by enhancing the gastric mucosal protection. The current treatments of GUS are targeted for either enhancing gastric mucosal defenses or counteracting injurious factors. The hallmark drugs have been the ones that reduce gastric acid secretion such as H2-receptor antagonists (e.g., ranitidine) and proton pump inhibitors (e.g., omeprazole) as well as antibiotic therapy for $\mathrm{H}$. pylori eradication ${ }^{7}$. The pharmacology of several agents that enhance the healing of peptic ulcers may be divided into three categories: (1) acid-antisecretory agents: a) H2 receptor antagonist drugs (Ranitidine, Famotidine, Cimitidine), b) Antimuscarinic agents (pirenzepine, telenzepine), c) proton pump inhibitors (Omeprazole, Pantoprazole,
Lansoprazole, Rabeprazole) (2) mucosal protective agents- carbenoxolone sodium, sucralfate and prostaglandin analogues (3) agents that promote healing through eradication of $\mathrm{H}$ pylori.

The high costs and side effects of long-term regimens combined with ulcer recurrence and some cases of refractoriness to conventional acid suppression therapies urge to search for new antiulcer agents addressed to enhance the healing of GU with fewer disadvantages than current treatments ${ }^{8,9}$. Thus, there is an urgent need to identify more effective and safe antiulcer agents. In this context, the use of medicinal plants for the prevention and treatment of different pathologies is in continuous expansion worldwide $^{10}$. Herbs, medicinal plants, spices, vegetables, and crude drug substances are considered to be a potential source to combat various diseases including gastric ulcer. In the scientific literature, a large number of medicinal plants with gastric antiulcer potential have been reported ${ }^{11-13}$.

According to WHO, herbal medicine, composed mainly of medicinal plants, are still curing diseases of an estimated 3.5 billion of the world's population as they can't afford western pharmacological drugs ${ }^{14}$. The Trigonella foenum graecum seed (Methi) is a very interesting one, for its pharmaceutical, industrial and alimentary valences. Herbs play a far great part in our everyday lives than most of us realize. The gastro-protective, cytoprotective and anti-ulcer effect of several other plants like Azadirachta indica (Neem), Ejambolana, Propolis ethanol extract, popular spice Anise-pimpinella anisum etc. are also studied by several other investigator ${ }^{15,16}$. They concluded that these plants possesses significant cytoprotective and anti-ulcer activities against experimentally induced gastric lesions possibly through promotion of mucosal defensive factors and anti-secretory or antioxidant status and decreasing lipid per oxidation. 
Trigonella foenum-graecum (Fenugreek, Methi) is an herbaceous annual of $10-40 \mathrm{cfl}$, aromatic and has compound leaves of 7 to $12 \mathrm{~cm}$ long. It is a herbal medicine used in many parts of world. Its leaves are used for their cooling properties and its seed for their carminative, tonic and aphrodisiac effects ${ }^{16}$. The seed contains alkaloids, steroidal sapogenins, fixed oil and mucilage ${ }^{17}$. It has been used for labor induction, aiding digestion and lactation ${ }^{18}$. Preliminary study on animal showed that Trigonella foenum-graecum seed reduced total acid and showed significant ulcer protective effects in ethanol-induced ulcer model ${ }^{19}$. Other studies reveal the possible hypoglycemic and antihyperlipidemic properties of Trigonella foenum-graecum seed in animals ${ }^{18}$.

\section{Materials and Methods:}

The present study was performed on 24 (twenty four) rats which were divided randomly into 4 groups each having 6 rats. Groups were labeled as group-A, group-B, group-C and group-D. The rats were aged between $8-10$ weeks of both sexes and weighing between 180-200 gm. They were kept for some days to acclimatize to the animal room conditions in medium sized metallic cages in the animal house of Pharmacology Department in Dhaka Medical college, Dhaka. They were allowed to live at room temperature' fed on standard pellets of rat food and allowed to drink water ad libitum.

\section{Materials:}

Aqueous and ethanolic extract of $T$. foenumgraecum seed

Omeprazole powder (Omenix suspensionIncepta pharmaceuticals Ltd.)

Absolute ethanol (99.9\%)

Distilled water (vehicle)

Normal rat food

Grouping of the animals: It was comprised of total 24 rats. They were divided into 4 groups each containing 6 rats labeled as group-A, group-B, group-C and group-D. This part of experiment was carried out to demonstrate the Histopathological evaluation of gastro protective effect of pretreatment with aqueous and ethanolic extract of $\mathrm{T}$. foenum-gracum seeds and omeprazole on ethanol induced gastric ulcer in experimental rats.

Group A : This group was served as control Group for extract treated groups and they were provided with $1 \mathrm{ml}$ of distilled water $(5 \mathrm{ml} / \mathrm{kg}$ body wt) orally by gastric tube.

Group B: They were orally administered each with aqueous extract of $T$. foenum-graecum seeds $(500 \mathrm{mg} / \mathrm{kg}$ body wt) by gastric tube.

Group C: They were orally administered each with ethanolic extract of $T$. foenum-graecum seed (500mg/kg body wt) orally by gastric tube.

Group D: They were provided with Omeprazole suspension $(20 \mathrm{mg} / \mathrm{kg}$ body wt) orally by gastric tube.

After 50 minutes of pretreated rats, $1 \mathrm{ml}$ of absolute ethanol $(5 \mathrm{ml} / \mathrm{kg}$ body wt.) was orally administered to all groups by gastric intubations. After 60 mins of administration of absolute ethanol all rats were sacrificed by an overdose of diethyl ether and were prepared for dissection. Each rat's stomach was removed and inflated with $10 \mathrm{ml}$ of $10 \%$ buffered formalin solution to fix the outer layer of the stomach. Each stomach was cut open along the greater curvature and rinsed with tap water to remove the contents and the mucosa was examined under the dissecting microscope grossly (10X) with a square-grid eyepiece to access the formation of ulcers.

\section{Histological examination:}

The stomach tissue samples were fixed in $10 \%$ buffered formalin solution overnight and then processed in an automated tissue processor. Stomach tissues were embedded in paraffim and subsequently sectioned by a Microtome and stained with Haematoxyline and Eosin stain. Each section was examined by light microscope with magnification of x10, x40 and x100 (oil immersion). 
Gastric damage was classified as follows: (Modified from Lacy et 1. 1982, cited by Habib, 1992).

\begin{tabular}{lll}
\hline O-Degree damage: & $:$ Normal mucosa and other coats \\
1-Degree damage: & $:$ Inflammatory changes in the lamina propria of Mucosa \\
2-Degree damage & $:$ Sloughing of lining epithelium, but gastric pit Epithelium is intact \\
3- Degree damage & $:$ Degeneration of pit epithelium with or without beginning of degenerative \\
& process in glandular epithelium, but not Completed. \\
4- Degree damage & $:$ Partial necrosis of gastric glands but erosion Is limited to mucous coat. \\
5- Degree damage & $:$ Sloughing of the whole thickness of mucous coat but there is no perforation. \\
6- Degree damage & $:$ Perforation.
\end{tabular}

The study was carried out to demonstrate Histopathological evaluation of gastro protective effect of pretreatment with aqueous and ethanolic extract of $\mathrm{T}$. foenum-graecum seed and omeprazole on ethanol induced gastric ulcer in experimental rats. The study was prospective experimental type and was conducted in the
Department of Pharmacology, Dhaka Medical College, Dhaka, from July 2008 to June 2009. All the data were analyzed by SPSS version 16.1.

\section{Ethical Clearance:}

This study was approved by the Ethical Review Committee of Dhaka Medical College, Dhaka.

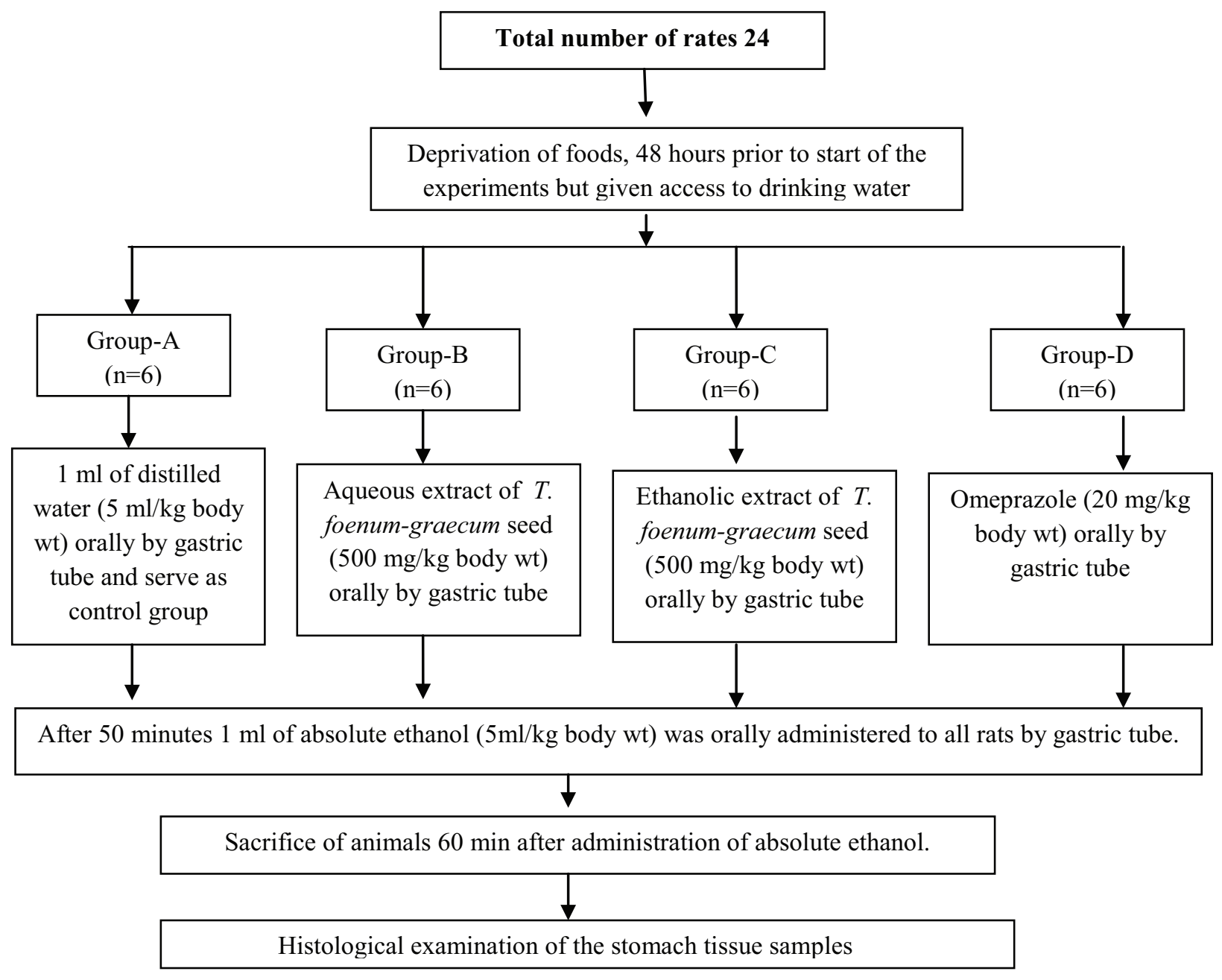

Fig.-1: Outline of the study 


\section{Results:}

In the current study gastro protective activity of aqueous and ethanolic extract of $T$. foenumgraecum seed and omeprazole was evaluated on ethanol induced gastric ulcer in experimental rats. Results of study revealed that in case of Experimental control group (group-A) where animals were treated only with ethanol there was a extensive damage of the gastric mucosa. Thick black or red lines were visible outside the stomachs, which indicated severe gastric damage. Gross examination showed a large amount of haemorrhagic lesions confined mostly in the gastric corpus. Histologically, lesion involved about two-third of the mucosa layer and exfoliation of the mucosal cells was detected. Meanwhile, red blood cells were present in the gastric mucosa and edematous submucosa was discovered as well with the appearance of marginated neutrophil around blood vessels and the superficial region of mucosal layer showed broad haemorrhagic condition (fig. 1) . Oral administration of omeprazole (group-D) reduced the formation of gastric lesions that was produced by absolute ethanol at inhibition percentage of $72.47 \%$. This treatment showed moderate cytoprotective effects. Histopathological evaluation showed intact mucosa layers with barely any exfoliation of epithelial cells. However, moderate edematous submucosa was detected with the appearance of marginated neutrophil around blood vessels and the superficial region of mucosal layer showed broad haemorrhagic condition (fig. 4). Pretreatment of aqueous and ethanolic extracts of $\mathrm{T}$. foenum-graecum seeds were used in study to evaluate the gastro protective activity of $\mathrm{T}$. foenum-graecum seeds. In animals Pre-treated with aqueous extract of $T$. foenum-gracum seeds ( group-B) significantly Prevented the formation of gastric lesions produced by absolute ethanol at an Inhibition percentage of $77.56 \%$. Histological examination showed intact mucosa layers with mild exfoliation of lining epithelial cells and a slight edematous submucosa was detected. However, the mucosal layer showed moderate haemorrhagic condition with the presence of red blood cells (fig. 2). Results also showed that in animals Pre-treated with ethanolic extract of $\mathrm{T}$. foenum-gracum seeds ( group-C) grossly showed Inhibition of $59.69 \%$ gastric lesions induced by absolute ethanol.
This pretreatment indicated reliable cytoprotective effects. Histological examination Showed mildiy fragile and eroded mucosa layers with moderate exfoliation of epithelial cells. In addition, edematous submucosa and red blood cells was detected but at a lesser degree(fig. $3)$.Results of the study revealed that $T$. foenumgracum seeds in the tested dosages showed no signs and symptoms of toxicity and the results of the study also have pointed out that the test plant showed gastro protective activity similar as synthetic antiulcer drug omeprazole which is mostly widely used as first line therapy in the treatment of gastric ulcer.

\section{Table-I}

Effect of pretreatment of aqueous and ethanolic extracts of $T$. foenum-graecum seeds and omeprazole on histological changes in the stomach (Degree of damage) in each group

\begin{tabular}{lccc}
\hline Groups & $\begin{array}{c}\text { Number } \\
\text { of } \\
\text { rats }\end{array}$ & $\begin{array}{c}\text { Total } \\
\text { number of } \\
\text { lesion }\end{array}$ & $\begin{array}{c}\text { Histological } \\
\text { changes in the } \\
\text { stomach (Degree } \\
\text { of damage) }\end{array}$ \\
\hline Group A & 6 & 32 & $1-4$ \\
Group B & 6 & 20 & $1-2^{* *}$ \\
Group C & 6 & 24 & $1-3^{* *}$ \\
Group D & 6 & 26 & $1-2^{* *}$ \\
\hline
\end{tabular}

Table-I: showed the histological changes in the stomach (Degree of damage) in each group. In control group (Group A) all the 1-4 degree Changes occurred. In Group B and in Group D only 1-2 degree changes occurred and in Group C-3 degree changes occurred. .** -very significant $(\mathrm{p}<0.001)$

Group A : This group was served as control group for extract treated groups and they were provided with $1 \mathrm{ml}$ of distilled water $(5 \mathrm{ml} / \mathrm{kg}$ body wt) orally by gastric tube.

Group B: They were provided with aqueous extract of $T$. foenum-graecum seed $(500 \mathrm{mg} / \mathrm{kg}$ body wt) orally by gastric tube.

Group C: They were provided with ethanolic extract of $T$. foenum-graecum seed $(500 \mathrm{mg} / \mathrm{kg}$ body wt) orally by gastric tube.

Group D: They were provided with Omeprazole suspension $(20 \mathrm{mglkg}$ body wt) orally by gastric tube. 


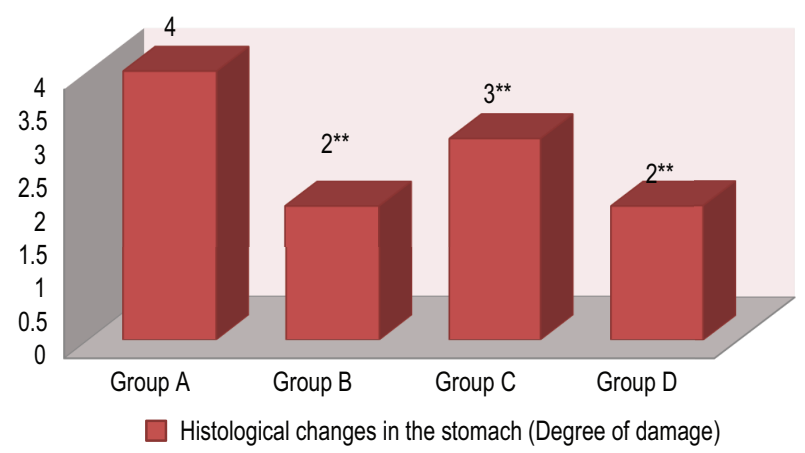

Fig.-1: Bar Diagram Showing the effect of pretreatment of aqueous and ethanolic extracts of $T$. foenum-graecum seeds and omeprazole on histological changes in the stomach (Degree of damage) in each group.

Multiple bar diagram showed that the histological changes in the stomach (degree of damage) in each group in the experiment. In experimental control group (Group A) all the 1 -4 degree changes occurred. In Group B and Group D only 1-2 degree changes occurred and group C 1-3 degree changes occurred. Statistically highly significant of difference were observed between the experimental groups and the control group $(\mathrm{P}$ value $<0.001) .{ }^{* *}$-very significant $(\mathrm{P}<0.001)$

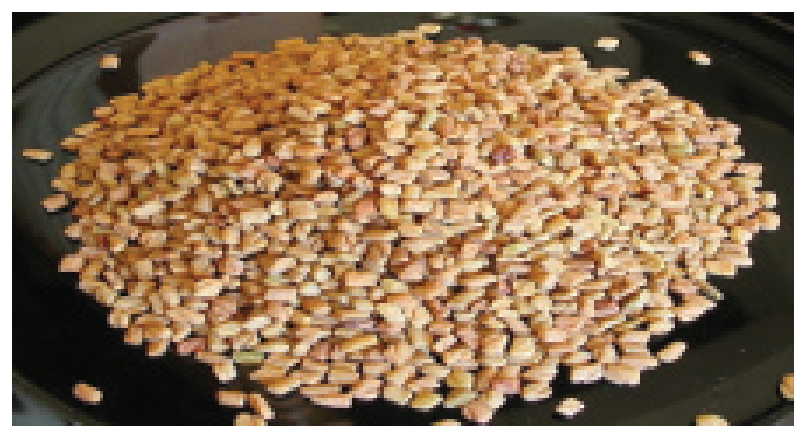

Fig.-2: Fenugreek (Methi)

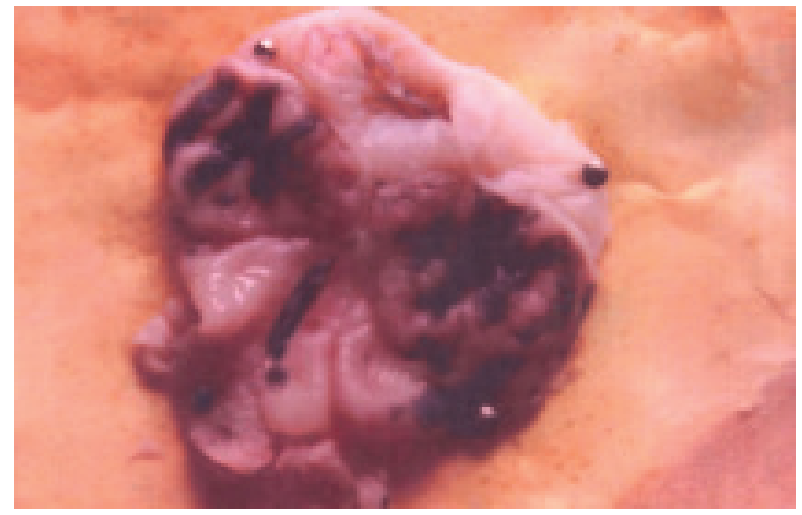

PM 1: Photograph of ethanol treated rat stomach showing lesions on gastric mucosal surface

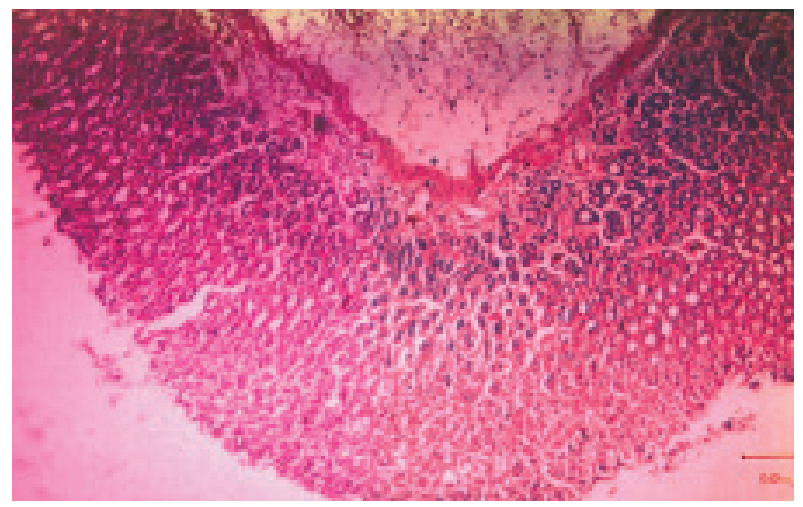

PM 2: Photomicrograph of normal (distilled water treated) rat gastric mucosa showing no histological change suggestive of gastric damage $(\mathrm{H} \& \mathrm{E})$

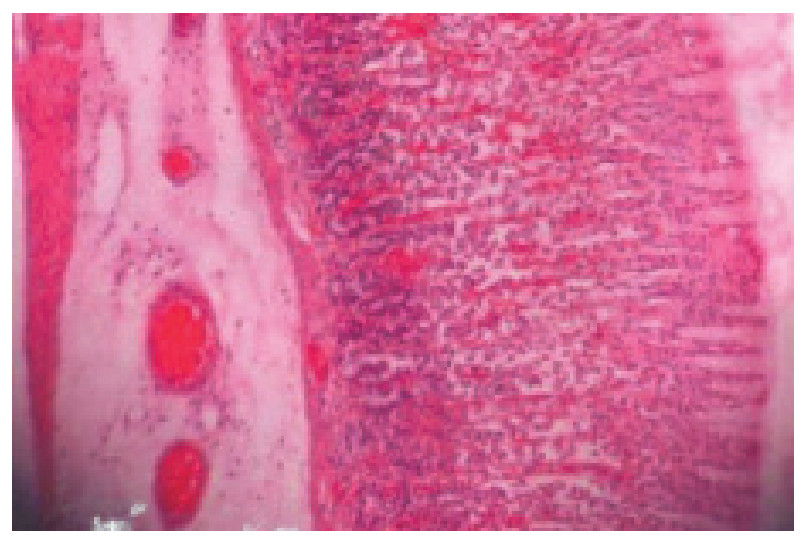

PM 3: Photomicrograph of ethanol (experimental control) treated rats gastric mucosa showing gastric mucosal damage. Severe disruption of the surface epithelium are seen and necrotic lesions penetrate deeply into mucosa with extensive edemas of submucosa and leucocyyte infiltration. (H \& E stain)

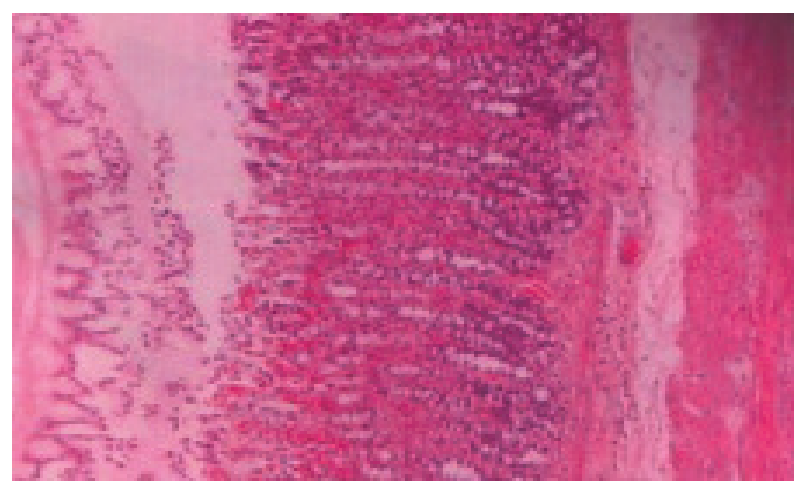

PM 4: Photomicrograph of aqueous extract of T. foenum-graecum seeds and ethanol treated rats gastric mucosa showing mild disruptions of surface epithelium are present but deep mucosal damage is absent. There is reduced submucosal edema and leucosytes infiltration. 


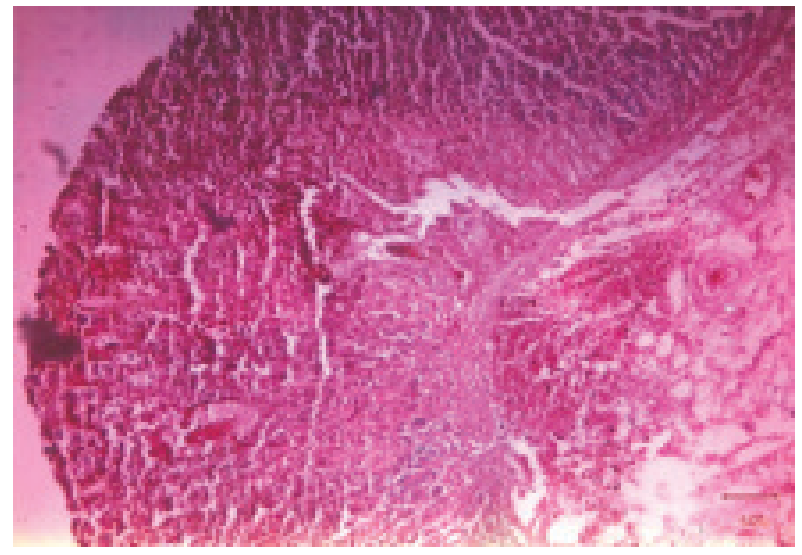

PM 5: Photomicrograph of enthanolic extract of $\mathrm{T}$. foenum-graecum seeds and ethanol treated rats gastric mucosa showing moderate disruptions of surface epithelium are present and deep mucosal damage is lees. There is reduced submucosal edema and leucosytes infiltration.

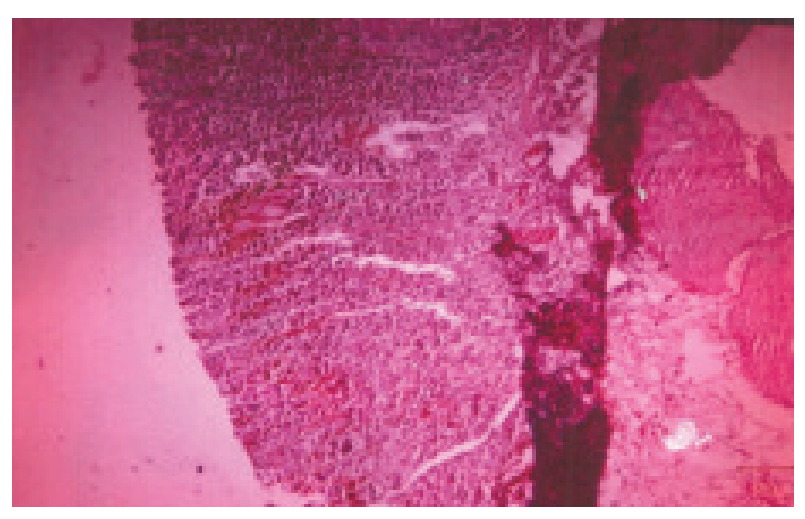

PM 6: Photomicrograph of omeprazole powder and ethanol treated rats gastric mucosa showing mild disruptions of surface epithelium are present but deep mucosal damage is absent. There is reduced submucosal edema and leucosytes infiltration (H \& E stain,x 100)

\section{Discussion}

The present study was carried out to evaluate the gastro-protective effect of Trigonella foenum graecum seed (Methi) seed on experimentally induced gastric-ulcer in rats. For this purpose, effect of aqueous and ethanolic extract of Trigonella foenum graecum seed (Methi) were demonstrated in ethanol induced gastric damage in rats. In addition, histological studies of rat stomach following administration of aqueous and ethanolic extract of $\mathrm{T}$. foenum- gracum seeds, Omeprazole and ethanol were also done. The seed have been used to treat a number of gastrointestinal disorder ${ }^{19}$. Although Trigonella foenum graecum seed (Methi) seed has not been well established in promoting protection toward gastric mucosa, many properties of Trigonella foenum graecum seed (Methi) seed as in antioxidant properties ${ }^{20}$ antiinflammation $^{21}$ and wound healing ${ }^{22}$ can be applied in elucidating the mode of protection produced by Trigonella foenum graecum seed (Methi) seed. In the present study, Absolute ethanol was used as agent to induce stomach ulcer in rats. The dose and routes of administration was selected according to Mequanente et al (2006) ${ }^{23}$ and Mahmood et al $(2005)^{24}$. Mequanente et al $(2006)^{23}$ and Mahmood et al (2005) ${ }^{24}$ also in their study showed that acute per oral administration of absolute ethanol $(5.0 \mathrm{ml} / \mathrm{kg})$ to fasted rats produced extensive necrosis of gastric mucosa and pretreatment with per oral administration of $\mathrm{T}$. foenum-gracum seeds extract could effectively and dose-dependently prevent such necrosis.

Pandian et $\mathrm{al}^{19}$ (2002) studied the effect of Trigonella foenum graecum seed (Methi) compared to omeprazole on ethanol-induced gastric ulcer. The aqueous extract and a gel fraction isolated from the seed showed significant ulcer protective effects. Their observations concluded that Trigonella foenum graecum seed (Methi) seed possess anti-ulcer potential.

In current study histopathological studies were carried out to histologically evaluate the gastroprotective efficacy of Trigonella foenum graecum seed (Methi) seeds. Results suggested that ethanol severely damaged the gastric mucosa by disrupting the gastric epithelial linings. Severe disruption of the surface epithelium were seen and necrotic lesions penetrate deeply into mucosa with extensive edemas of submucosa and leucocyyte infiltration.. Administration of synthetic gastroprotective drug omeprazole significantly reduced the gastric damage and cellular infiltration. However administration of aqueous and ethanolic extract of $\mathrm{T}$. foenum-gracum 
seeds along with ethanol significantly reduced the gastric sloughing, infiltration, edema, hemorrhage and tissue proliferation .Hence aqueous extract of $T$. foenum-gracum seeds showed more effective results as synthetic antiulcer drug omeprazole. The above mentioned results are in accordance with previous studies( Mahmood et al 2005) ${ }^{24}$.

The experiment also showed (table-I, Fig-) that the lowest degree of gastric damage occurred in group-B (pretreated with aqueous extracts of Trigonella foenum graecum seed) followed by group-D (pretreated with omeprazole powder $20 \mathrm{mg} / \mathrm{kg}$ body wt) and then group-C (pretreated with ethanolic extract of Trigonella foenum graecum seed). In experimental control group (Group A) all the 1 -4 degree changes occurred. In Group B and Group D only 1-2 degree changes occurred and group C 1-3 degree changes occurred. In 2005 in a study Mahmood et al. ${ }^{24}$ investigated the gastric protective effect of honey in combination with aqueous and ethanolic extract of Trigonella foenum graecum seed (Methi) in rats against ethanol-induced gastric damage that revealed that honey in combination with aqueous seed extract was significantly more effective than honey alone or in combination with alcoholic extract in preventing gastric lesions formation ${ }^{24}$. Their observations showed that Trigonella foenum graecum aqueous seed extract posse's gastroprotective potential.

The exact mechanism of gastroprotection of $\mathrm{T}$ foenum-gracum has not established yet. Several works suggested some possible mechanism. $\mathrm{T}$ foenum-gracum contains flavonoids ${ }^{25}$ which is an antioxidant and reported to have antiulcer properties ${ }^{24}$. Pandian et al (2002) ${ }^{19}$ stated that T. F.G. reduced peroxidation index with increased antioxident enzyme activity and gastric lesion reduction in hydrochloric acid- ethanol treated rats. Kaurc et al (2002) $)^{26}$ stated that, aqueous and alcohalic extract of T.F.G leaves were shown to have antioxidant property.T.F.G leave extracts were classified in high antioxidant activity from plant source antioxidants. The aqueous extract of T.F.G seed revealed positive result for the polyphenol test. T.F.G leaves were found to have high phenolic contents. The study also showed the correlation between phenolic content (Flavonoids) and antioxidant effect. Mequanente et $\mathrm{al}^{23}$ stated that the gastroprotective effect of $\mathrm{T}$ foenum-gracum may be attributed to antioxidant properties of polyphenols. Saurez et al(1996) ${ }^{27}$ stated that the fenugreek seeds exert their healing activity through the flavonoids since flavonoids are reported to protect the mucosa by preventing the formation of lesions by various necrotic agents. The fenugreek seeds also prevented the rise in lipid peroxidation induced by aspirin presumably by enhancing antioxidant potential of the gastric mucosa thereby lowering mucosal injury. These observations showed that the fenugreek seeds possess gastroprotective effect.

Although Trigonella foenum graecum seed (Methi) has not been well established in promoting protection toward gastric mucosa, many properties of Trigonella foenum graecum seed with its anti-inflammatory, anti-oxidant and in wound healing can be applied in elucidating the mode of protection produced by Trigonella foenum graecum seed (Methi) in this study. The aqueous extracts of Trigonella foenum graecum seed (Methi) in this study then the ethanolic extract of Trigonella foenum graecum seed (Methi) significantly inhibited the action of ethanol in inducing ulcer. Histopathological evaluation of the gastroprotective effect is statistically significant when compared to control group.

\section{Conclusion}

Histopathological evaluation of aqueous and ethanolic extracts of Trigonella foenum graecum seed (Methi) and omeprazole shows gastro protective properties. In this study there was no statistical significanct difference was observed between aqueous and ethanolic extracts of Trigonella foenum graecum seed (Methi) in histological gastro protective effects. Nevertheless, both extracts of Trigonella foenum graecum seed (Methi) were able to deliver satisfying gastro protective effects in preventing gastric mucosal lesions formation induced by absolute ethanol. It was concluded that aqueous and ethanolic extracts of Trigonella foenum graecum seed (Methi) is significantly reduced 
the gastric sloughing and infiltration induced by ethanol. Therefore, it is documented that aqueous and ethanolic extracts of Trigonella foenum graecum seed (Methi) is efficacious in reducing the gastric toxicity mainly due to its antioxidant potential. Further investigation of Trigonella foenum graecum seed (Methi) in inducing gastro protectiveness needs to be carried out because it might be beneficial in treating a variety of diseases that are related to gastric mucosal injury.

\section{References}

1. Hasan M, Ali SMK, Azad Khan AK. Peptic ulcer disease in. Bangladesh - an endoscopy survey. Gut 1985; 16: A. 1117.35

2. Feldman M, Friedman LS, Brandt LJ, editors. Sleisenger and Fordtran's Gastrointestinal and Liver Disease. 9th ed. Philadelphia : Elsevier ;2010.p.861.

3. Mc QKR. Alimentary Tract in Current Medical Diagnosis and Treatment. Editors Tierney Jr LM, Mc Phee SJ, Papadakis MA. $46^{\text {th }}$ edition, International edition. McGraw-Hill. New York ; 2007: 554-663.

4. R. Dimaline and A. Varro, "Attack and defence in the gastric epithelium-a delicate balance," Experimental Physiology, vol.92, no. 4, pp. 591-601, 2007.

5. M. I. Gomes Silva and F. C. Florenc。 de Sousa, "Gastric Ulcer Etiology," in Peptic Ulcer Disease, J. Chai, Ed., InTech, 2011

6. M. Magierowski, K. Magierowska, S. Kwiecien, and T. Brzozowski, "Gaseous mediators nitric oxide and hydrogen sulfide in the mechanism of gastrointestinal integrity, protection and ulcer healing," Molecules, vol. 20, no. 5, pp. 9099-9123, 2015

7. P. Malfertheiner, F. K. Chan, and K. E. McColl, "Peptic ulcer disease," The Lancet, vol. 374, no. 9699, pp. 1449-1461, 2009.

8. C. Scarpignato, I. Pelosin i, and F. Di Mario, "Acid suppression therapy: where do we go fromhere?" Digestive Diseases, vol. 24, no. 1-2, pp. 11-46, 2006.

9. E. Sheen and G. Triadafilopoulos, "Adverse effects of long-term proton pump inhibitor therapy," Digestive Diseases and Sciences, vol. 56, no. 4, pp. 931-950, 2011.

10. K. S. De Lira Mota, G. E. N. Dias, M. E. F. Pinto et al., "Flavonoids with gastroprotective activity," Molecules, vol. 14, no. 3, pp. 979-1012, 2009.

11. M. A. Abdulla, K. A. A. Ahmed, F. H. Al-Bayaty, and Y.Masood, "Gastroprotective effect of Phyllanthus niruri leaf extract against ethanol-induced gastricmucosal injury in rats," African Journal of Pharmacy and Pharmacology, vol. 4, no. 5,pp. 226230, 2010.
12. A. A. Mahmood, A. A. Mariod, F. Al-Bayaty, and S. I. Abdel- Wahab, "Anti-ulcerogenic activity of Gynura procumbens leaf extract against experimentallyinduced gastric lesions in rats,"Journal of Medicinal Plant Research, vol. 4, no. 8, pp. 685-691, 2010.

13. S. Q.Wasman, A. A. Mahmood, H. Salehhuddin, A. A. Zahra, and I. Salmah, "Cytoprotective activities of Polygonum minus aqueous leaf extract on ethanolinduced gastric ulcer in rats,"Journal of Medicinal Plant Research, vol. 4, no. 24, pp. 2658-2665, 2010.

14. Ghai A. Medicinal Plants of Bangladesh. $2^{\text {nd }}$ edition, Dhaka. Asiatric Society of Bangladesh;2003: 1-35.

15. Liu $\mathrm{CF}$, Lin $\mathrm{CC}$, Lin $\mathrm{MH}$, Lin YS, Lin $\mathrm{SC}$. Cytoprotection by Propolisethanol Extract of Acute Absolute Ethanol-induced Gastric Mucosal Lesions. Am J Chin Med. 2002 ; 30(2-3):245-54.

16. Al MA, Alhaider AA, Mossa JS, Al-Sohaibani MO, Rafatullahs. Aqueous Suspension of Anise "Pimpinellaanisum" Protect Against Chemically Induced Gastric Ulcers. World J Gastroentero. 2007; 13(7):1112-18.

17. Chopra RN, Hondaand LD, Kapur. Chapra's Indigenous Drugs of India. Academic Publishers. Calcutta, New Delhi, India;1982: 582

18. Evans WC. Trease and Evans Pharmacognosy. $5^{\text {th }}$ edition WB Saunders, London;2000:188.

19. Pandian RS, Anuradha CV, Viswanathan P. Gastroprotective Effect of fenugreek seed (Trigonella foenum graecum) on Experimental Gastric Ulcer in Rats. J Ethnopharmacol. 2002;81(3):393-97.

20. Basch E, Kuo G, Smith M. Therapeutic Applications of fenugreek. Altern Med Rev. 2003;8: 20-28.

21. Anuradha CV and Ravikumar P. Anti-lipid per Oxidative Activity of Seed of Fenugreek (Trigonella foenum graecum). Medical Science Research.1998; $26: 317-21$

22. Mustafa MR, Mahmood AA, Salmah I. Effects of Trigonella foenum-graecum Seed Extract in Combination with Honey on Experimental Wound Healing in Rats. International Journal of Molecular Medicine and Advance Science. 2005; 1(1):29-33.

23. Mequanente S, Makonnen E, Asfaw DA. Gastroprotective Effect of Aqueous trigonella feonum-gracum and linumussitatissimum Seed Extracts in Mice. Pharmacology online. $2006 ; 2: 324-34$.

24. Mahmood AA, Sidik KS. Anti-ulcer and Gastroprotective Effects of Honey in Combination with Trigonella foenum graecum Seed Extract on Experimental Gastric Ulcer in Rats. International Journal of Molecular Medicine and Advance Science. 2005; 1(3):225-9.

25. Nasir, S. and R. Nagar, 1997. Anti-oxidant flavonoids in common Indian foods. South Asian J. Preventive Cardiol. 1: 33-35

26. Kaur C, Kappor HC. Antioxidant activity and total pheolic content of some Asian vegetable. I J Food Sci Technol2002; 37: 153-161 